\title{
Pachydermoperiostosis: scintigraphic, thermographic, plethysmographic, and capillaroscopic observations
}

\author{
ADEL G. FAM, HYACINTH CHIN-SANG, AND COLIN A. RAMSAY \\ From the Departments of Medicine and Radiology, University of Toronto, and Rheumatic Disease Unit, \\ Sunnybrook Medical Centre, Toronto, Ontario, Canada
}

SUMMARY A unique case of pachydermoperiostosis, multiple epiphyseal dysplasia, and secondary osteoarthritis is described. An additional interesting feature was the presence of acroosteolysis of the distal phalanges of fingers and toes. Scintigraphic, thermographic, plethysmographic, and capillaroscopic studies suggested increased blood flow through clubbed fingers, raising the possibility that this may play a role in the pathogenesis of pachydermoperiostosis.

Pachydermoperiostosis (primary or idiopathic hypertrophic osteoarthropathy) is a rare, often familial disease characterised by digital clubbing, cylindrical thickening of legs and forearms, sebaceous gland overactivity, hyperhidrosis, and symmetrical irregular periosteal ossification predominantly affecting the distal ends of long bones. ${ }^{1-3}$

Reported here is a unique case of pachydermoperiostosis and multiple epiphyseal dysplasia. Scintigraphic, thermographic, plethysmographic, and capillaroscopic findings suggested increased blood flow through clubbed digits. An additional, interesting feature was the presence of acroosteolysis of the distal phalanges of fingers and toes, a finding which has rarely been described in pachydermoperiostosis. $^{3-5}$

\section{Case report}

A 56-year-old single Italian woman presented in 1979 with a history of clubbed fingers and toes associated with deformities of feet, knees, and elbows dating back to childhood. Excessive greasiness of skin, profuse perspiration of hands and feet, and marked thickening of the skin of the face, forearms, hands, and legs had been present for an indeterminate period. She had noticed pain in the legs and forearms since her late teens. Arthritis involving hips, knees, elbows, wrists, and ankles had been noted for

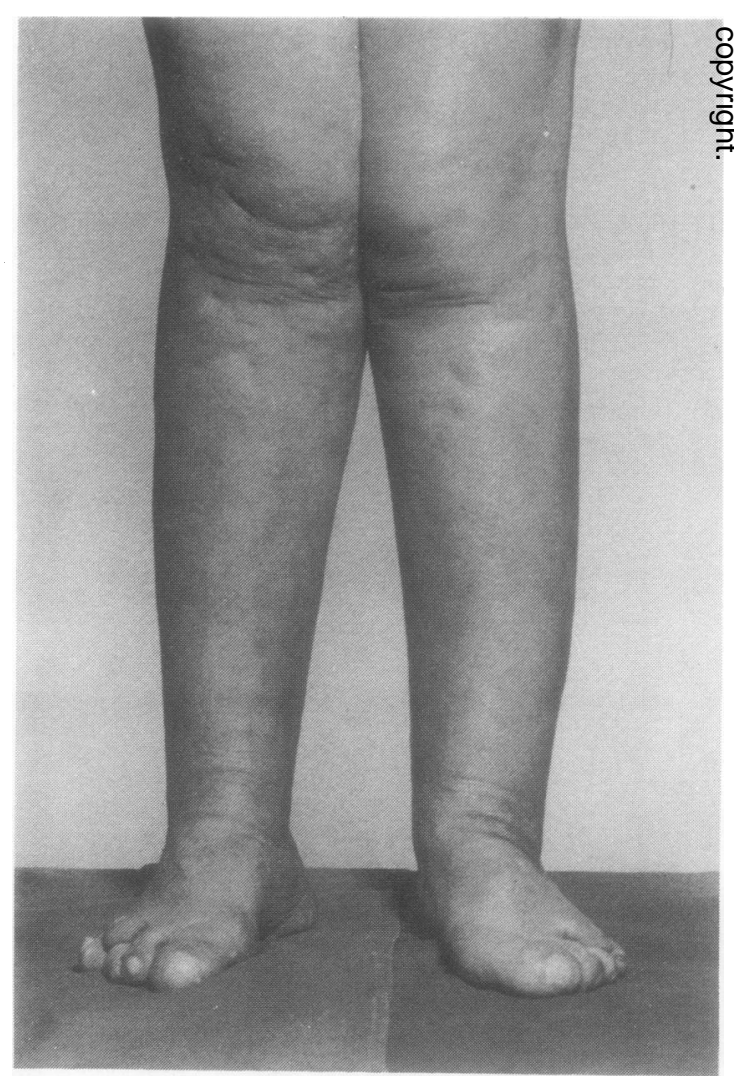

Fig. 1 Symmetrical cylindrical enlargement of legs, genu valgus deformity, and clubbing of the toes. 


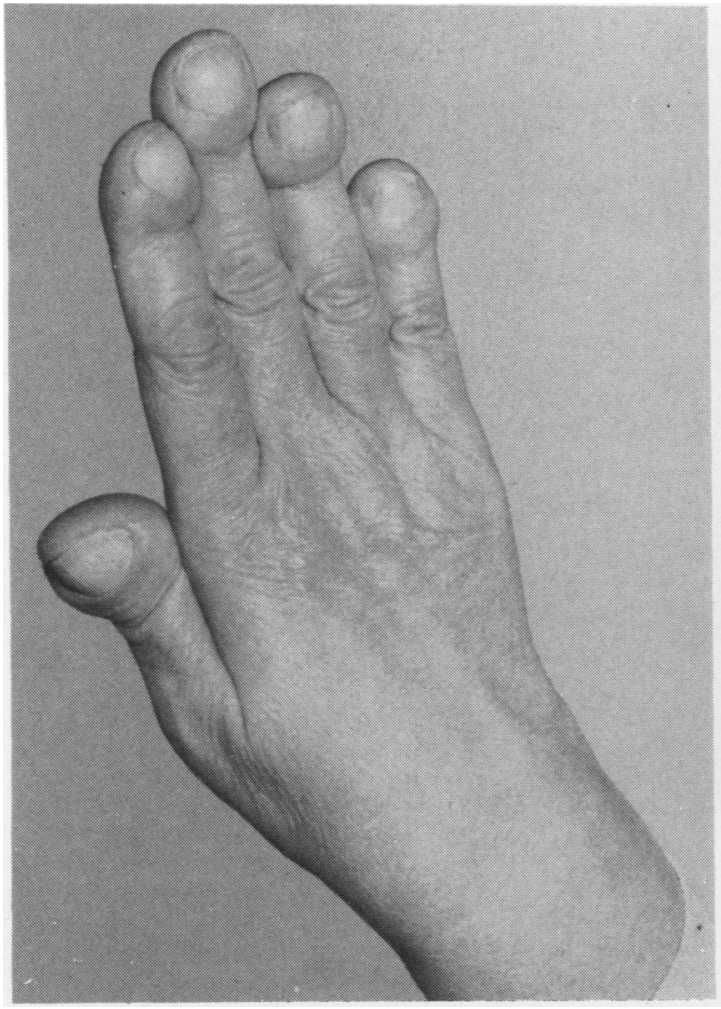

Fig. 2 Patient's right hand showing clubbing and thickening of the digits.

many years. Pain and stiffness in knees and hips became progressively worse during the previous 2 years, and she experienced great difficulty walking. There was no family history of the disease.

She was of average intelligence and $130 \mathrm{~cm}(4 \mathrm{ft}$ 3 in) tall. Pertinent findings included an oily skin, general hyperhidrosis, deep furrowing of the forehead, symmetrical cylindrical enlargement of legs and forearms (Fig. 1), with irregular thickening of tibiae and fibulae, and unusually large hands and feet

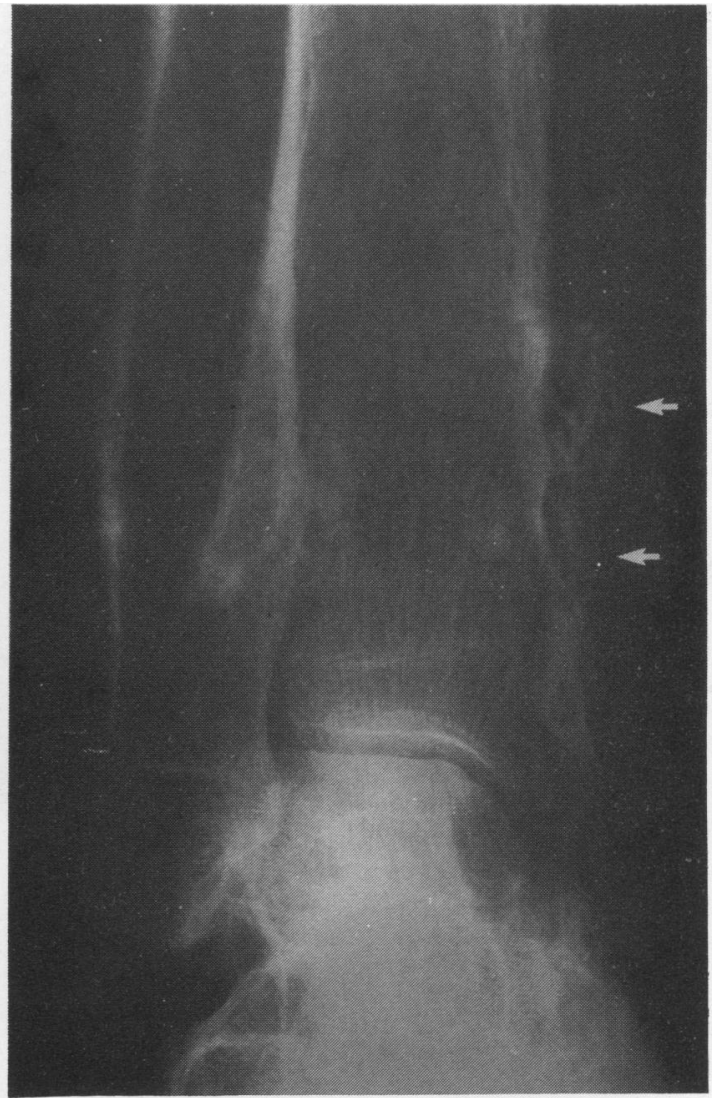

Fig. 3 Right ankle showing diffuse, shaggy periosteal thickening of distal end of the tibia (arrows) and fibula and slanting of the ankle joint mortise from the lateral to the medial side.

with gross bulbous clubbing (Fig. 2). She had restricted movement of hip, knee, ankle, talocalcaneal, shoulder, elbow, and wrist joints; flexion deformity and crepitus of the elbows; valgus deformity of the knees without effusion; and planovalgus

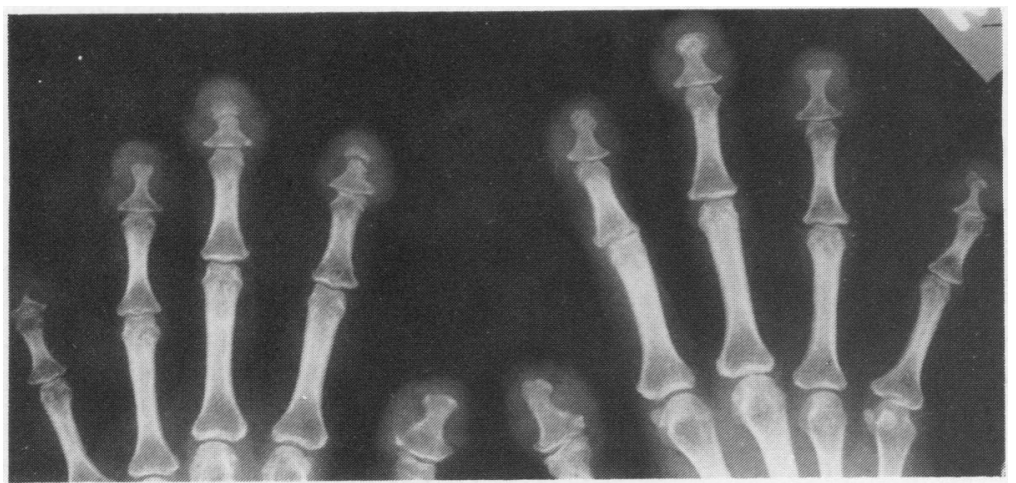

Fig. 4 Radiographs of hand showing resorption of distal phalanges. 


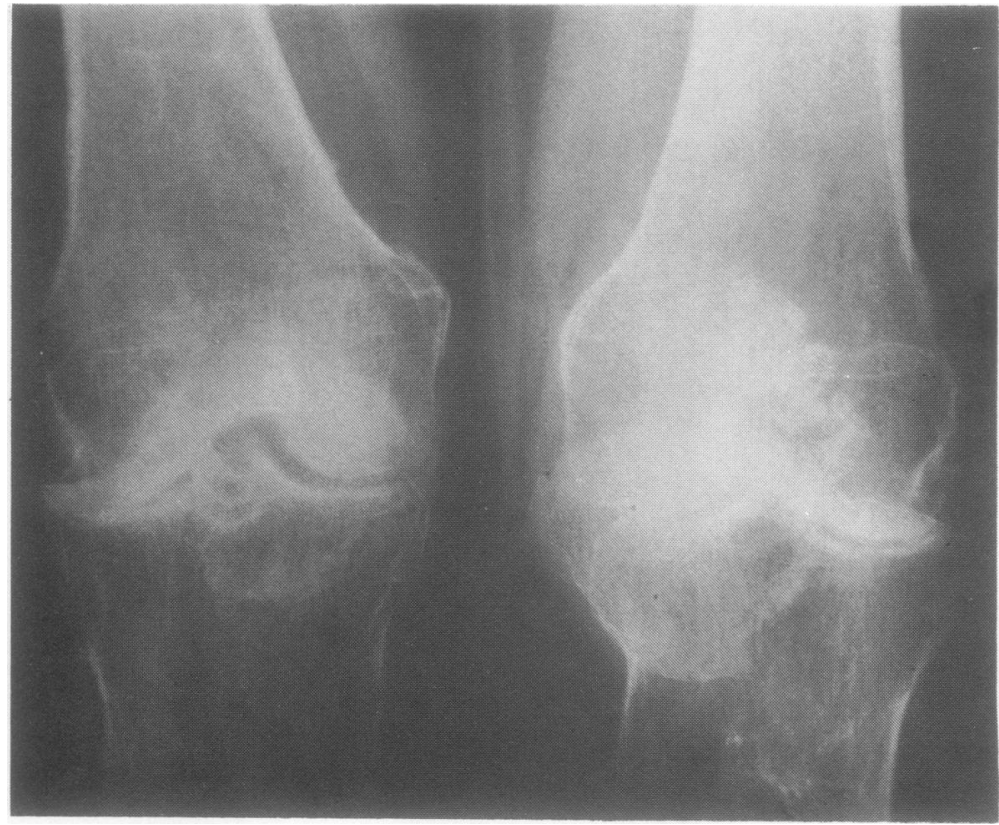

Fig. 5 Anteroposterior radiographs of knees showing angular tibial condyles with irregular articular surfaces, degenerative arthritis, and osseous bodies in the left knee.

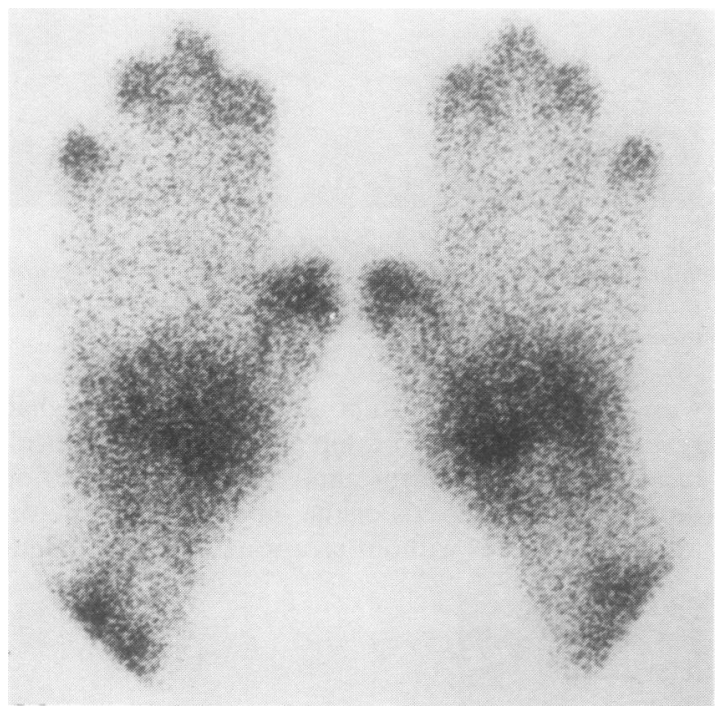

Fig. 6 Scintigraphs of the hands showing accumulation of the isotope in the finger tips.

deformity of the feet, with short metatarsals and stubby toes. Neurological examination was unremarkable.

Her haemoglobin was $14 \cdot 2 \mathrm{~g} / \mathrm{dl}$, leucocyte count $9200 / \mathrm{mm}^{3}\left(9 \cdot 2 \times 10^{9} / 1\right)$, erythrocyte sedimentation rate $28 \mathrm{~mm} / \mathrm{h}$, and normal serum calcium, phosphorus, alkaline phosphatase, uric acid, protein electrophoresis, thyroid indices, creatinine, and urine analysis. Tests for rheumatoid and antinuclear factors were negative, the VDRL was nonreactive, and total haemolytic complement was normal. Radiographic examination showed generalised soft-tissue swelling with digital clubbing, irregular periosteal proliferation with cortical thickening of distal parts of the tibiae, fibulae, radii, and ulnae (Fig. 3), and resorption of the distal phalanges of the fingers (Fig. 4) and toes. Multiple epiphyseal abnormalities, including irregular tibial surfaces, deficient epiphyses of tibial tuberosities (Fig. 5), flattening of femoral heads, and irregularities of distal humeral epiphyses and tarsal and carpal bones, were also observed. Other findings included a characteristic downward inclination of the distal tibial articular surface from lateral to medial side (Fig. 3); short, broad metatarsals, and secondary osteoarthritis of hip, knee, ankle, talocalcaneal, shoulder, elbow, and wrist joints. Radiographs of the chest, skull, and spine were normal.

\section{SPECIAL STUDIES}

A ${ }^{99 m}$ Tc methylene diphosphonate bone scintiscan revealed pericortical linear concentration of the radionuclide along the distal tibial and fibular shafts, and increased uptake in the elbows and knees. The blood pool images also showed accumulation of the nuclide in the finger tips (Fig. 6). Thermography of the hands showed hyperthermia of the distal ends of 


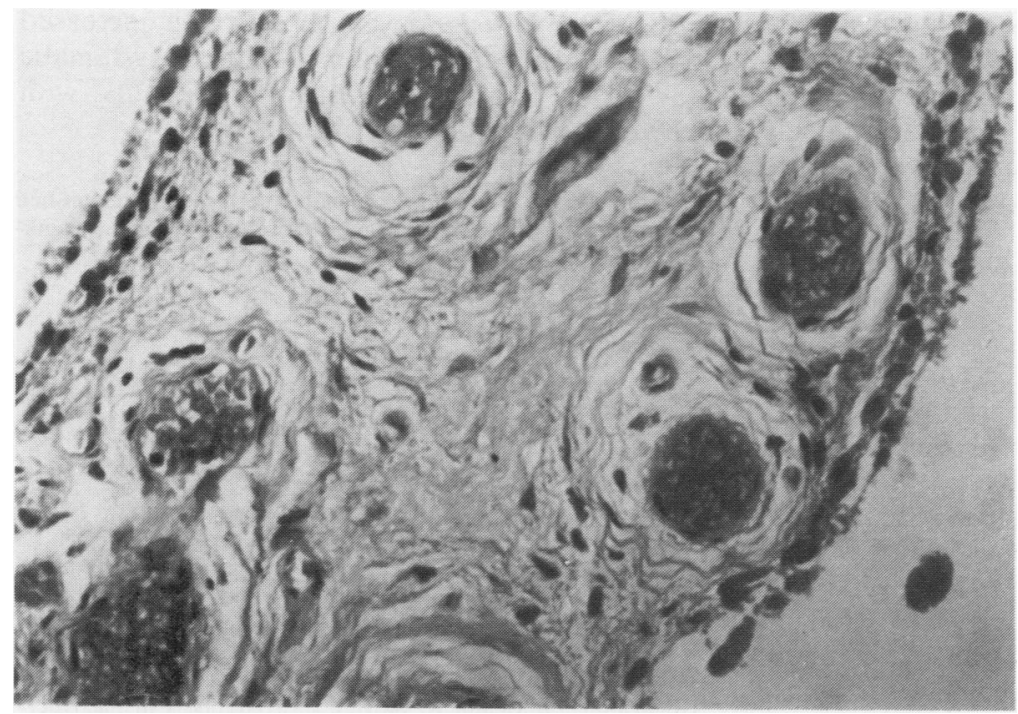

Fig. 7 Synovial biopsy from the right knee showing mild synovial lining cell hyperplasia and thickening of subsynovial blood vessels. (Haematoxylin and eosin, $\times 235$ ).

several digits, most marked in the thumbs and left index finger. Photoelectric plethysmography (method of Challoner and Ramsay ${ }^{6}$ ) revealed increased blood flow to several of the clubbed fingers as compared with a control. Nail bed capillary microscopy revealed slight capillary enlargement and increased tortuosity. A needle synovial biopsy of the right knee showed mild synovial lining cell hyperplasia, increased vascularity, and marked thickening of small subsynovial blood vessels with fibrosis (Fig. 7).

\section{Discussion}

Points of interest in this report pertain to clinical features and results of special investigations. The patient described fits all the classic features of pachydermoperiostosis. ${ }^{1-5}$ Although patients with pachydermoperiostosis often complain of arthralgia and bone pains, deforming arthritis is not a prominent feature. ${ }^{1-57}$ In this patient, however, severe degenerative arthritis, particularly of knees, wrists, elbows, and hips, dominated the clinical picture. She was of below average height, and further radiographic studies revealed typical findings of multiple epiphyseal dysplasia (MED), ${ }^{x-11}$ with defective epiphyseal development, marked deformities of articular surfaces, secondary osteoarthritis, short stubby metatarsals, and characteristic sloping of the ankle mortise (slant sign). ${ }^{\gamma-10}$ Spondyloepiphyseal dysplasia was excluded by the lack of spinal involvement.

Another unusual finding in this case was the presence of acroosteolysis of the distal phalanges of fingers and toes. This rare feature of pachydermoperiostosis is not widely recognised..$^{3-5}$ The occurrence of acroosteolysis in association with finger clubbing in these patients helps to differentiate pachydermoperiostosis from other conditions of which osteolysis is a feature. ${ }^{4}$

The association of pachydermoperiostosis and MED has not to our knowledge been previously reported. A familial incidence has been observed in both conditions. The 2 diseases are often transmitted as an autosomal dominant with variable expressivity. ${ }^{1-58-11}$

There is also evidence in some cases of MED for a pattern of autosomal recessive inheritance. ${ }^{12}$ The occurrence of MED in association with pachydermoperiostosis in this case is probably coincidental and raises the possibility of multiple gene abnormalities. No suggestion of either condition was found in other members of the family, suggesting that the genetic defect arose de novo in this patient.

Synovial histopathological findings in our patient included mild synovial lining cell hyperplasia, increased vascularity, and marked thickening of subsynovial blood vessels. Synovial membrane abnormalities were described in 2 other patients with pachydermoperiostosis..$^{7-13^{*}}$ Similar pathological changes were observed in both, and electron microscopy in one of them ${ }^{13}$ revealed multilayered basement membrane laminae around small subsynovial blood vessels. It is of interest that morphological and ultrastructural studies of the synovial membrane in secondary hypertrophic osteoarthropathy have also shown prominent microvascular abnormalities. ${ }^{14}$

The scintigraphic findings in this case are analogous to those described in secondary hypertrophic 
osteoarthropathy: symmetrical pericortical uptake over long bones, increased concentration of the radionuclide by involved joints, and accumulation of the nuclide in the finger tips. ${ }^{15-16}$ In a recent study from Yugoslavia ${ }^{7}$ similar scintigraphic abnormalities were observed in 10 of 13 patients with pachydermoperiostosis.

Little is known of the pathogenesis of pachydermoperiostosis with the exception of the genetic factor. Similarities in clinical manifestations and anatomical findings in pachydermoperiostosis and secondary hypertrophic osteoarthropathy have suggested a common pathogenetic mechanism. ${ }^{1}$ Evidence of an increased rate of blood flow through the affected parts has been demonstrated in patients with secondary hypertrophic osteoarthropathy. ${ }^{17-19}$ Scintigraphic, thermographic, plethysmographic, and capillaroscopic studies in our patient strongly suggested an increased blood flow in the clubbed fingers. Our findings are in agreement with the Yugoslavian study. ${ }^{7}$ Hypervascularity of distal parts of fingers was observed in all 5 patients in whom arteriography was performed. Scintigraphy in 10 of 13 patients of the same study showed accumulation of the radionuclide in the distal ends of digits, suggesting that the metabolic activity and/or blood flow to the clubbed digits is increased. These results are contrary to 2 previous studies of peripheral blood flow in pachydermoperiostosis. In one study of 2 patients ${ }^{2}$ angiography revealed decreased blood flow through the forearms and hands, while water-seal plethysmography of the distal forearms showed a normal flow rate. In a second study ${ }^{20}$ of a case of pachydermoperiostosis angiography showed obstruction of blood flow through the forearms and hands, and nail bed capillaroscopy showed scanty, irregular capillary loops. It should be emphasised, however, that these 2 studies were performed at a time when the disease was thought to be inactive. The disease was probably still active in our patient, as suggested by the scintigraphic and thermographic findings and the presence of persistent bone pain and tenderness. These observations are in agreement with the view that peripheral blood flow is increased during the early active phase of pachydermoperiostosis and is reduced in the late inactive phase. $^{1220}$ The postulate is further supported by the results of pathological studies showing highly vascular periosteal new bone in early phases of the disease and compact, relatively avascular bone in late stages. ${ }^{1}$

The question whether local vascular disturbances relate to the pathogenesis of pachydermoperiostosis remains unresolved. The present study indicates that such a relationship may exist and that the active phase of the disease is associated with increased blood flow through the clubbed digits. A systematic study of a larger population of patients with pachydermoperiostosis is needed.

The authors thank Dr Frances Leung for performing the nail bed capillaroscopy and Mrs Janet Hays for preparation of the manuscript.

\section{References}

${ }^{1}$ Vogl A, Goldfischer S. Pachydermoperiostosis: primary or idiopathic hypertrophic osteoarthropathy. Am J Med 1962; 33: 166-87.

${ }^{2}$ Rimoin D L. Pachydermoperiostosis (idiopathic clubbing and periostosis). Genetic and physiologic considerations. $N$ Engl $J$ Med 1965; 272: 924-31.

${ }^{3}$ Herbert D A, Fessel W J. Idiopathic hypertrophic osteoarthropathy (pachydermoperiostosis). West J Med 1981; 134: 354-7.

4 Guyer P B, Brunton F J, Wren M W G. Pachydermoperiostosis with acro-osteolysis. A report of five cases. J Bone Joint Surg 1978; 60B: 219-23.

${ }^{5}$ Hedayati H, Barmada R, Skosey J L. Acrolysis in pachydermoperiostosis. Primary or idiopathic hypertrophic osteoarthropathy. Arch Intern Med 1980; 140: 1087-8.

6 Challoner A V J, Ramsay C A. A photoelectric plethysmograph for the measurement of cutaneous blood flow. Phys Med Biol 1974; 19: 317-28.

7 Jajic I, Pecina M, Krstulovic B, Kovacevic D, Pavicic F, Spaventi S. Primary hypertrophic osteoarthropathy (PHO) and changes in the joints. Scand J Rheumatol 1980; 9: 89-96.

${ }^{8}$ Barrie H, Carter C, Sutcliffe J. Multiple epiphyseal dysplasia. Br Med J 1958; ii: 133-7.

${ }^{9}$ Leeds N E. Epiphyseal dysplasia multiplex. $A J R$ 1960; 84: 506-10.

${ }^{10}$ Murphy M C, Shine I B, Stevens D B. Multiple epiphyseal dysplasia. Report of a pedigree. J Bone Joint Surg 1973; 55A: 814-20.

${ }^{11}$ Gibson T, Highton J. Multiple epiphyseal dysplasia: a family study. Rheumatol Rehabil 1979; 18: 239-42.

12 Gamboa I, lisker R. Multiple epiphyseal dysplasia tarda. A family with autosomal recessive inheritance. Clin Genet 1974; 6: 15-9.

${ }^{13}$ Lauter S A, Vasey F B, Huttner I, Osterland C K. Pachydermoperiostosis: studies on the synovium. J Rheumatol 1978; 5: 85-95.

${ }^{14}$ Schumacher Jr H R. Articular manifestations of hypertrophic pulmonary osteoarthropathy in bronchogenic carcinoma. A clinical and pathologic study. Arthritis Rheum 1976; 19: 629-36.

15 Rosenthall L, Kirsh J. Observations on radionuclide imaging in hypertrophic pulmonary osteoarthropathy. Radiology 1976; 120: 359-62.

16 Altman R D, Tenenbaum J. Hypertrophic osteoarthropathy. In: Kelley W N, Harris E D, Ruddy J, Sledge C B, eds. Textbook of Rheumatology. 1st ed. New York: Saunders, 1981: 1647-57.

17 Vogl A, Blumenfeld S, Gutner L B. Diagnostic significance of pulmonary hypertrophic osteoarthropathy. Am J Med 1955; 18: 51-65.

${ }^{18}$ Holling H E, Brodey R S, Boland H C. Pulmonary hypertrophic osteoarthropathy. Lancet 1961; ii: 1269-74.

19 Rutherford R B, Rhodes B A, Wagner H N. The distribution of extremity blood flow before and after vagotomy in a patient with hypertrophic pulmonary osteoarthropathy. Dis Chest 1969; 56: 19-23.

${ }^{20}$ Kerber R E, Vogl A. Pachydermoperiostosis. Peripheral circulatory studies. Arch Intern Med 1973; 132: 245-8. 